\title{
Case-control study of lung cancer among sugar cane farmers in India
}

\begin{abstract}
Devendra K Amre, Claire Infante-Rivard, André Dufresne, Prakash M Durgawale, Pierre Ernst
\end{abstract}

\begin{abstract}
Objectives-To investigate the risk of lung cancer among sugar cane farmers and sugar mill workers.

Methods-A case-control study was conducted based in six hospitals in the predominantly sugar cane farming districts of the province of Maharashtra in India. Newly diagnosed, histologically confirmed cases were identified from these hospitals between May 1996 and April 1998. Other cancers were chosen as controls and matched to cases by age, sex, district of residence, and timing of diagnosis.

Results-Adjusting for confounders, an increased risk of lung cancer was found for workers ever employed on a sugar cane farm (odds ratio (OR) 1.92 , 95\% confidence interval (95\% CI) 1.08 to 3.40). Increased risks were found for work involving preparation of the farm (OR $1.81,95 \%$ CI 0.99 to 3.27 ) and burning of the farm after harvesting (OR 1.82, 95\% CI 0.99 to 3.34). Non-significant increases in risks were found for harvesting the crop (OR 1.41, 95\% CI 0.70 to 2.90) and processing the cane in the mills (OR 1.70, 95\% CI 0.20 to 12.60 ).

Conclusions-Exposure to fibres of biogenic amorphous silica (BAS) formed from silica absorbed from the soil and deposited in the leaves of the sugar cane crop or crystalline silica formed as a result of conversion of BAS to cristobalite at high temperatures may account for the increased risks of lung cancer among sugar cane farmers.

(Occup Environ Med 1999;56:548-552)
\end{abstract}

Joint Departments of Epidemiology and Biostatistics, and Occupational Health, McGill University, 1020 Pine Avenue (West), Montreal, PQ, Canada H3A 1A2

D K Amre

C Infante-Rivard

A Dufresne

P Ernst

Department of Preventive and Social Medicine, Krishna Institute of Medical Sciences, Karad, Satara, Maharashtra, India 415110

P M Durgawale

Correspondence to: Dr Devendra K Amre, Joint Departments of Epidemiology and Biostatistics, and Occupational Health, 1130 Pine Avenue West, Montreal, PQ, Canada H3A $1 \mathrm{~A} 3$. Telephone 001514398 4229; fax 0015143987435 ; devendra@epid.lan.mcgill.ca (email address)

Accepted 8 March 1999
Keywords: sugar cane farmers; lung cancer; biogenic silica

In some crops such as rice, sugar cane, wheat, and millet, silica may be absorbed from the soil. Although the exact mechanisms for the uptake, accumulation, and deposition are unknown, it is postulated that soluble monosilic acid $\left(\mathrm{H}_{4} \mathrm{SiO}_{4}\right)$ taken up from the soil is deposited in the epidermal cells of the leaves. ${ }^{1}$ This deposited silica, called biogenic silica, is amorphous and can exist in the form of fibres. Recently, there has been growing interest in the health effects of exposure to these biogenic amorphous silica (BAS) fibres because of their morphological similarity with asbestos fibres. ${ }^{23}$

Toxicological studies indicate that exposure to BAS fibres can promote skin cancer in mice and mesothelioma in rats. ${ }^{45}$ There are also reports of increased incidence of oesophageal cancer after ingestion of these fibres. ${ }^{6-9} \mathrm{~A}$ recent epidemiological study among rice farmers in California reported an increased prevalence of radiological lung opacities, possibly due to exposure to these fibres. ${ }^{10}$ Although exposure to fibres within the respirable range has been reported for workers farming sugar cane and rice, ${ }^{11-13}$ the occurrence of adverse health outcomes remains to be convincingly demonstrated.

Sugar cane farmers are regularly exposed to BAS fibres. Some epidemiological studies suggest an increased risk of lung cancer or mesothelioma in these workers, ${ }^{14-16}$ but others do not. ${ }^{17}{ }^{18}$ Most of these studies were carried out on cane farmers in North America. In countries such as India, sugar cane farming techniques differ from those common to North America. Sugar cane farmers in North America burn the fields before harvesting to reduce the leafage and facilitate cutting the crop. Most of these activities are mechanised. In India, however, the fields are not burnt before harvesting. During harvesting, a stem of about $0.3 \mathrm{~m}$ is left in the ground. This stem subsequently produces another harvest. After two subsequent harvests, the whole field is burnt and a new crop is sown. Most of these farming activities are done manually.

The objective of the present case-control study was to estimate the risk of lung cancer from sugar cane farming in the province of Maharashtra in India.

\section{Methods}

The province of Maharashtra, situated in the west of India, is the leading sugar cane producing region in the country. Sugar cane is farmed on about 430000 hectares of land. The 105 sugar producing mills account for $35 \%$ of the sugar produced in the country. ${ }^{19}$ Of the 31 districts in the province, sugar cane is primarily farmed in the districts of Kolhapur, Sangli, Satara, Pune, and Ahmednagar. The farming population of this region was selected for the study.

Cases and controls were identified at six major cancer treatment centres in the province. Four of these centres were located within the study area. Many migrant sugar cane harvesters come from the Marathwada region of the province. To cover this population, one main cancer referral centre that deals with this population was selected. Some of the cases occurring within the study area were likely to be directly referred to the Tata Memorial Hos- 
pital and Cancer Research Institute in Mumbai, the main cancer referral centre of the province, so to achieve as complete an ascertainment of cases as possible from the defined geographical area, this hospital was also selected.

Newly diagnosed, histologically confirmed cases of primary lung cancer were identified from the admission registers maintained at the selected hospitals from May 1996 to April 1998. Only those patients whose medical files included a histopathological confirmation report were selected. For each case, three controls were identified from the registers maintained at the radiotherapy departments of the respective hospitals from where the cases were recruited. Controls were diagnosed with other cancers and matched to the case for age ( \pm 10 years), sex, district of residence, and timing of diagnosis within 2 months of that of the case. Controls similar to the case on the matching factors were selected consecutively. When more than three controls were eligible, those closest to the age of the case were selected.

Patients and controls were interviewed by questionnaire face to face at the hospital by trained interviewers. When developing the questionnaire, two questionnaires previously used for studies conducted among agricultural workers and the standard respiratory questionnaire of the American Thoracic Society were consulted. However, as these could not be adapted to our study population, we developed a questionnaire after surveying the prevalent sugar cane farming and processing operations in the region. Data on the sociodemographic characteristics of the subjects with details on occupational history were collected. Data on lifelong work experiences (including jobs held, duration of each job, departments, job titles, and exposures within each job) were obtained. A separate section on farming elicited information on the type of crop farmed as well as the nature and duration of each farming activity. For sugar cane farming, subjects were asked about specific tasks such as ploughing or tilling and cleaning the farm, sowing and cutting the crop, and burning the field after cutting. Finally, information was collected on specific jobs (crane operation, boiler operation, bagasse handling, etc) and activities within such jobs during cane processing in the sugar mills.

Information on the main confounding variables - such as smoking, exposure to asbestos, income, education, farming other crops, and family history of lung cancer-was also sought. Exposure to asbestos was defined as involvement in any one of the following jobs: insulating furnaces, repairing ships, construction work, maintaining boilers, manufacturing cement sheets, manufacturing refractory bricks, and fitting pipes.

STATISTICAL ANALYSIS

Data were coded and entered in the Paradox (Windows) spreadsheet. Analysis was carried out with procedures available in the SAS software. Conditional logistic regression analysis, accounting for the matching in the design was used. Odds ratios (ORs) (as estimates of risk ratios) and their approximate $95 \%$ confidence intervals (95\% CIs) were determined.

In the multiple regression analysis, sugar cane farming was examined as a dichotomous (yes, no) exposure variable. Each specific activity - such as preparation of the farm (including activities such as ploughing or tilling, cleaning, and sowing), cutting the crop (harvesting), and burning the field after cutting the crop-was also individually analysed. Employment in the processing of cane in the sugar mill was analysed separately. As the number of subjects involved in these jobs was small, it was not possible to explore individual activities within these jobs.

A cumulative duration of employment index for each sugar cane farming activity and all the activities combined was calculated as follows: cumulative employment in each individual activity $=$ number of days a year worked in the particular activity times the number of years employed on a sugar cane farm; cumulative employment in all the activities combined = sum of the number of days a year worked in each individual activity times the number of years employed on a sugar cane farm.

The cumulative indices were analysed both as continuous and categorical variables. When using them as categorical variables, those who had never farmed sugar cane belonged to the reference category and the other categories were constructed so that there was a roughly equal proportion of subjects within them.

When variables were used as continuous, linearity assumptions were checked. To do this, they were first categorised into quartiles and a plot of the logits (log odds of the outcome variable) with the midpoint of the quartiles was examined. Assumptions were satisfied when the plots showed a linear relation. ${ }^{20}$

Smoking was put in the model either as categorical (never, ever) or as pack-years (continuous or categorical) of smoking. To control for any residual confounding, the final models included pack-years of smoking. The interaction between smoking and sugar cane farming was assessed. Smoking, asbestos exposure, and other confounding variables such as family history of lung cancer, income, education, and farming of other crops (rice, wheat, jowar, bajra, etc) were accounted for in the analysis.

\section{Results}

A total of 128 cases of lung cancer were identified at the six hospitals during the study period. Of these, 118 patients were successfully interviewed $(92.2 \%)$. Of the 10 patients who were not interviewed, histological confirmation of the diagnosis could not be obtained for four. The remaining six patients could not be traced or refused to be interviewed (two and four, respectively). Of the 310 controls that were eligible, 298 (96.1\%) were interviewed. A histological confirmation could not be obtained for the 12 controls not interviewed.

Three controls each could be obtained for 81 $(68.6 \%)$ cases, two each for $18(15.3 \%)$ cases, and one each for $19(16.1 \%)$ cases. For five $(4.2 \%)$ cases, not all controls from the same 
Table 1 Distribution of sociodemographic and confounding variables $(n(\%))$ in the comparison populations

\begin{tabular}{|c|c|c|}
\hline Characteristic & $\begin{array}{l}\text { Cases }(n(\%)) \\
(n=118)\end{array}$ & $\begin{array}{l}\text { Controls }(n(\%)) \\
(n=298)\end{array}$ \\
\hline \multicolumn{3}{|l|}{ Age (y): } \\
\hline $25-34$ & $3(2.5)$ & $5(1.7)$ \\
\hline $35-44$ & $13(11.0)$ & $18(6.1)$ \\
\hline $45-54$ & $26(22.0)$ & $67(22.6)$ \\
\hline $55-64$ & $39(33.1)$ & $120(40.4)$ \\
\hline$>64$ & $37(31.4)$ & $88(29.5)$ \\
\hline \multicolumn{3}{|l|}{ Sex: } \\
\hline Men & $96(81.4)$ & $241(80.9)$ \\
\hline Women & $22(18.6)$ & $57(19.1)$ \\
\hline \multicolumn{3}{|l|}{ Education: } \\
\hline None & $49(41.5)$ & $100(33.6)$ \\
\hline Primary & $39(33.1)$ & $131(44.0)$ \\
\hline Secondary & $26(22.0)$ & $57(19.1)$ \\
\hline Post-secondary & $4(3.4)$ & $10(3.3)$ \\
\hline \multicolumn{3}{|c|}{ Income / y (rupees): } \\
\hline$<5000$ & $15(12.7)$ & $47(15.8)$ \\
\hline $5001-10000$ & $55(46.6)$ & $142(47.8)$ \\
\hline $10001-15000$ & $29(24.6)$ & 79 (26.6) \\
\hline $15001-20000$ & $18(15.3)$ & $20(6.7)$ \\
\hline$>20000$ & $1(0.9)$ & $10(3.4)$ \\
\hline \multicolumn{3}{|l|}{ Smoking: } \\
\hline Never & $52(44.1)$ & $170(57.1)$ \\
\hline Ever & $66(55.9)$ & $128(42.9)$ \\
\hline \multicolumn{3}{|l|}{ Pack-years: } \\
\hline 0 & $52(44.1)$ & $170(57.1)$ \\
\hline $1-225$ & $29(24.6)$ & $61(20.5)$ \\
\hline$>225$ & $37(31.3)$ & $67(22.4)$ \\
\hline \multicolumn{3}{|c|}{ Exposure to asbestos: } \\
\hline No & $112(94.9)$ & $292(98.0)$ \\
\hline Yes & $6(5.1)$ & $6(2.0)$ \\
\hline \multicolumn{3}{|c|}{ Farming crops besides sugar cane: } \\
\hline No & $51(43.2)$ & $135(45.3)$ \\
\hline Yes & $67(56.8)$ & $163(54.7)$ \\
\hline \multicolumn{3}{|c|}{ Family history of lung cancer: } \\
\hline No & $117(99.9)$ & $289(97.0)$ \\
\hline Yes & $1(0.1)$ & $9(3.0)$ \\
\hline
\end{tabular}

$\star$ One rupee is equivalent to US $\$ 0.03$.

area of residence as the case could be selected. The remaining controls were selected from the district geographically closest to the residence of the case. For seven $(5.9 \%)$ cases and 10 $(3.4 \%)$ controls, the next of kin provided information. In most instances it was the spouse. Patients with cancers of the oral cavity $(14.9 \%)$ and female reproductive system (11.3\%) formed the largest proportion of control diseases. Cancer of the pharynx $(8.7 \%)$ and oesophageal cancer $(7.7 \%)$ were the other major diagnoses in the controls.

Table 1 shows the demographic characteristics of the subjects. Except for the 35-44 year age group, in which there were $11.0 \%$ of cases compared with $6.1 \%$ of controls, the age distribution was similar. Subjects were predominantly male $(81 \%)$. There were more cases in

Table 2 Lung cancer risks for ever working in a sugar cane farm and for specific cane farming activities *

\begin{tabular}{lccl}
\hline Occupation or job & Cases (n (\%)) & Controls (n (\%)) & OR (95\% CI) \\
\hline Ever worked in a cane farm: & $39(33.1)$ & $64(21.5)$ & $1.92(1.08$ to 3.40$)$ \\
$\quad$ Yes & $79(66.9)$ & $234(78.5)$ & 1.00 \\
$\quad$ No & $36(30.5)$ & $60(20.1)$ & $1.81(0.99$ to 3.27$)$ \\
Ever prepared cane farm: & $82(69.5)$ & $238(79.9)$ & 1.00 \\
$\quad$ Yes & $15(12.7)$ & $27(9.1)$ & $1.41(0.70$ to 2.90$)$ \\
$\quad$ No & $103(87.3)$ & $271(90.9)$ & 1.00 \\
Ever harvested cane: & $30(25.4)$ & $48(16.1)$ & $1.82(0.99$ to 3.34$)$ \\
$\quad$ Yes & $88(74.6)$ & $250(83.9)$ & 1.00 \\
$\quad$ No & $2(1.7)$ & $3(1.0)$ & $1.70(0.20$ to 12.60$)$ \\
Ever burnt cane field: & $116(98.3)$ & $295(99)$ & 1.00 \\
$\quad$ Yes & No &
\end{tabular}

^Adjusted for smoking (pack-years), exposure to asbestos, income, education, family history of lung cancer, and farming of other crops. the lower education categories and likewise in the lower income groups.

Smoking, exposure to asbestos, education, income, family history of lung cancer, and farming other crops were considered as confounding variables. Table 1 shows the distribution of these variables in the cases and controls. More cases (56\%) than controls (43\%) reported ever smoking, which was reflected in the distribution of pack-years of smoking. Only 12 $(2.9 \%)$ subjects reported work involving exposure to asbestos, six of these were cases. Most of these reported having worked as construction workers. A history of lung cancer in the family was reported less often in cases. An equal proportion of cases and controls had farmed other crops (rice, wheat, jowar, bajra, etc) besides sugar cane.

The conditional logistic regression analysis (table 2) showed that the risks for lung cancer were significantly increased for those who had ever worked on a sugar cane farm, compared with those who never had (OR 1.92; 95\% CI 1.08 to 3.40 ). Further exploration of the risks within individual farming activities, showed that risks were increased for workers involved in the preparation of the crop (OR 1.81; 95\% CI 0.99 to 3.27 ) and for those involved in the burning of the crop after harvesting (OR 1.82; $95 \%$ CI 0.99 to 3.34 ). The risk for workers who harvested the crop was increased but was not significant (OR $1.41 ; 95 \%$ CI 0.70 to 2.90 ).

For workers involved in the processing of the sugar cane in the mills, risk was increased but the $95 \%$ CI was wide as only two cases and three controls reported ever working in a sugar cane mill (OR $1.70 ; 95 \%$ CI 0.20 to 12.60 , table 2). The few workers in the mills precluded further analysis of risks within individual activities.

The association between duration of employment (years) and the risk of lung cancer was compatible with a linear trend on the logistic scale in which the ORs increased by a factor of 1.21 (1.02 to 1.40) for each 10 year duration of employment on the sugar cane farm. Workers involved in the burning of the sugar cane farms for $>210$ days of their lifetime, had $>2.5$ times greater risk than those never involved in this activity (OR $2.60 ; 95 \%$ CI 1.20 to 5.70 , table 3). Slightly lower, but increased risks were also found for workers involved in preparing the farm for $>1160$ days of their lifetime (OR 2.30; $95 \%$ CI 1.10 to 4.70 ). No significant increase in risk was found with increasing duration of harvesting. For the combined duration of work in all the activities, the risk was found to increase significantly for workers with $>1470$ days of work in their lifetime (OR 2.30; 95\% CI 1.20 to 4.40) compared with never working on the sugar cane farm.

Smoking (table 4) modified the relation between sugar cane farming and lung cancer. Sugar cane farmers who smoked $>225$ packyears of cigarettes over their lifetime had an almost sixfold greater risk for lung cancer than those subjects who neither smoked nor farmed sugar cane. The risk for lung cancer for the combined effects of smoking and farming 
Table 3 Cumulative duration of employment in individual and combined sugar cane farming activities and risks * for lung cancer

\begin{tabular}{|c|c|c|c|}
\hline $\begin{array}{l}\text { Cumulative duration of } \\
\text { employment (days) }\end{array}$ & Cases $(n(\%))$ & Controls (n (\%)) & OR $(95 \% C I)$ \\
\hline \multicolumn{4}{|c|}{ Preparation of the farm: $†$} \\
\hline 0 & $82(69.5)$ & $238(79.9)$ & 1.00 \\
\hline $1-1160$ & $15(12.7)$ & $32(10.7)$ & $1.30(0.60$ to 2.60$)$ \\
\hline$>1160$ & $21(17.8)$ & $28(9.4)$ & $2.30(1.10$ to 4.70$)$ \\
\hline \multicolumn{4}{|l|}{ Burning of the farm: $†$} \\
\hline 0 & $88(74.6)$ & $250(83.9)$ & 1.00 \\
\hline $1-210$ & $13(11.0)$ & $28(9.4)$ & $1.30(0.60$ to 2.80$)$ \\
\hline$>210$ & $17(14.4)$ & $20(6.7)$ & $2.60(1.20$ to 5.70$)$ \\
\hline \multicolumn{4}{|l|}{ Cutting of the crop: $\dagger$} \\
\hline 0 & $103(87.3)$ & $271(90.9)$ & 1.00 \\
\hline $1-750$ & $8(6.8)$ & $14(4.7)$ & $1.40(0.50$ to 3.70$)$ \\
\hline$>750$ & $7(5.9)$ & $13(4.4)$ & $1.50(0.50$ to 3.90$)$ \\
\hline \multicolumn{4}{|l|}{ All activities combined: $\neq$} \\
\hline 0 & $79(66.9)$ & $234(78.5)$ & 1.00 \\
\hline $1-1470$ & $16(13.6)$ & $33(11.1)$ & $1.40(0.70$ to 2.80$)$ \\
\hline$>1470$ & $23(19.5)$ & $31(10.4)$ & $2.30(1.20$ to 4.40$)$ \\
\hline
\end{tabular}

^Adjusted for smoking (pack-years), exposure to asbestos, income, education, family history of lung cancer, and farming other crops.

†Cumulative duration of employment $=$ number of days worked in either preparation or cutting, or burning of the farm per year $\times$ number of years cane was farmed.

¥Cumulative duration of employment for all activities combined $=$ number of days worked in preparation, cutting, and burning of the farm per year $\times$ number of years cane was farmed.

Table 4 Interaction between smoking and employment on sugar cane farm *

\begin{tabular}{lll}
\hline $\begin{array}{l}\text { Pack-years of } \\
\text { smoking }\end{array}$ & $\begin{array}{l}\text { Never farmed sugar cane } \\
\text { OR }(95 \% \mathrm{CI})\end{array}$ & $\begin{array}{l}\text { Farmed sugar cane } \\
\text { OR }(95 \% \mathrm{CI})\end{array}$ \\
\hline 0 & $1.00 \dagger$ & $1.10(0.50$ to 2.20$)$ \\
$1-225$ & $1.45(0.70$ to 3.00$)$ & $2.70(0.90$ to 8.00$)$ \\
$>225$ & $1.41(0.70$ to 2.80$)$ & $5.89(2.30$ to 14.70$)$ \\
\hline
\end{tabular}

* Odds ratios are based on the logistic model with interaction terms for smoking (pack-years) and sugar cane farming, controlling for exposure to asbestos, income, education, family history of lung cancer, and farming of other crops.

†Reference category.

sugar cane was greater than the product of their individual effects.

\section{Discussion}

We found an increased risk of lung cancer in sugar cane farmers. Workers involved in the preparation of the farm and in the burning of the farm after harvesting the crop had the highest risks. The risk was also found to increase with increasing years of employment on the sugar cane farm and with increasing number of days worked over the lifetime in preparing and burning the fields and for all the individual activities combined. Non-significant increases in risk were found for sugar cane farmers involved in harvesting of the crop and for workers employed in the sugar cane mills.

Sugar cane farmers are exposed to BAS fibres. ${ }^{11} 12$ Exposure to such fibres with aspect ratios $>3: 1$, has been reported during the burning of the crop before harvesting, during harvesting, and during the processing of the cane in the sugar mills. Although not documented for sugar cane farmers, during activities such as burning of the farms after harvesting and preparation of the burnt farm (ploughing, tilling, sowing), workers are likely to be exposed also to airborne crystalline silica formed as a result of conversion of the BAS during the burning of the field. Such temperature dependent conversion and subsequent exposure to crystalline silica (cristobalite) has been reported during the processing of diatomaceous earth. ${ }^{21}$ Besides exposures to silica, during the burning of the farms it is possibile that carcinogenic elements are formed and released into the air. Some authors have considered the likelihood of exposure to polycyclic aromatic hydrocarbons ${ }^{11}{ }^{12}$ during the actual burning operations and the subsequent preparation of the burnt area. An increase in risk found during these activities in the present study could possibly be explained by exposures to these substances either singly or in combination.

We found a non-significantly increased risk of lung cancer in workers employed in the sugar cane mill. Although the small numbers precluded further analysis of risk within specific activities, a study of activities within the sugar cane mill (walk through surveys and personal communication with sugar mill workers) highlighted several issues. Besides possible exposure to BAS fibres, during certain activities, workers are also likely to be exposed to crystalline silica. This is especially true during the use of crushed sugar cane as fuel for evaporating the juice; during this process (which is carried out in large boilers), the high temperature in the boilers $\left(1000-1200^{\circ} \mathrm{C}\right)$ is likely to convert the BAS to crystalline silica. Workers involved in activities within the boiler areasuch as feeders, sweepers, supervisors, etc-are thus at risk of exposure to both forms of silica. A study of a larger sample of mill workers would be necessary to assess the effects of such exposures.

We found that smoking modified the risk of lung cancer associated with sugar cane farming. This risk increased with increasing number of packs of cigarettes smoked. Although it is too early to draw definite conclusions on the interaction, it is possible that the BAS fibres or crystalline silica may interact with the carcinogens within the smoke to facilitate the development of cancer. Such interactions have been well documented for exposure to asbestos fibres. $^{22}$

Few epidemiological studies have assessed the risk of lung cancer in sugar cane farmers. Rothschild and Mulvey ${ }^{15}$ reported a more than twofold increase in risk of lung cancer (OR 2.40; $95 \%$ CI 1.70 to 3.60) in Louisiana sugar cane farmers after controlling for the effects of smoking and exposure to asbestos. However, risks within specific activities were not assessed. Brooks et $a l^{16}$ found an increase in risk of lung cancer in sugar cane farmers in Florida (OR 1.80; 95\% CI 0.50 to 7.50 ). No details were provided, however, on the risks during individual farming activities. Miller et $a l^{17}$ found a modest increase in mortality from lung cancer in a cohort of sugar cane farmers in Hawaii (relative risk 1.26; 95\% CI 0.89 to $1.78)$. In this study, data on specific job activities were not available. As most of the cohort members had short work durations on the sugar cane plantations, it is possible that latency was too short to find an increased risk.

In the present study, some of the limitations of the previous studies were overcome. Efforts were made to reduce selection bias. Cases were ascertained at all the major hospitals that deal with the geographically defined sugar cane farming population and that most likely to treat cases from among the migrant harvesting workers. Also, to cover any cases not referred to 
the designated hospitals, the main cancer referral centre of the province was included in the study. Response rates achieved for both cases and controls were high.

Histologically confirmed cases and controls were included. Few if any of the subjects changed their jobs, and information on exposure was obtained directly from $94 \%$ cases and $96.6 \%$ controls. Use of other cancer cases as controls likely enhanced comparability of recall. As a result of this, it is likely that misclassification of either exposure or disease was minimised.

There were, however, some limitations to the study. Other cancer cases besides lung cancers were selected as controls. No restriction was placed on the choice of control diseases as sugar cane farming has not been found to be associated positively or negatively with any cancer with certainty. It is, however, possible that the exposure distribution within such controls is different (and likely greater) than that in the source population of the cases and could result in bias towards the null. Although selection of a population based control group would have been ideal for the study base principle, adequate information for its selection was not available.

The interviewers used for the study, although trained, were nevertheless not blinded to the case-control status. This could have resulted in overestimation of risk if cases were probed with more insistence.

It was not possible to obtain quantitative exposure information for the study subjects. Years of employment and the cumulative duration indices used as surrogates for exposure duration and intensity, may not represent accurately the actual exposures. More detailed exposure information will be necessary to study the putative association and any doseresponse relations.

Although efforts were made to gather accurate information on the main confounding variables, it is possible that other exposures not accounted for may be responsible for the increased risks. Some reports suggest that exposure to pesticides such as DDT (banned but still widely used in India) may be associated with an increased risk of lung cancer. ${ }^{23-25}$ Although the frequency of use of any pesticide within the study population was reported to be negligible (oral communication with the Sugar Cane Workers Federation, personal interviews with sugar cane farmers), confounding by such exposure cannot be ruled out with certainty.

The present study is the first to assess the risks of lung cancer in sugar cane farmers in the developing countries. The limited data presently available are from sugar cane farming populations in North America. Sugar cane farming activities are different in countries like India. This, associated with the lack of use of personal protective equipment, may result in different levels and intensity of exposures to BAS fibres. As already mentioned there is also the possibility of exposure to crystalline silica and polycyclic aromatic hydrocarbons. Future epidemiological studies supplemented with exposure measurements need to be carried out in other sugar cane farming and processing communities to add more information on the possible risks for lung cancer in this population.

We thank the following personnel for providing the necessary permission and facilities to conduct the study at their hospitals: Dr KA Dinshaw, Dr V Sharma, and Dr SS Shastri, Tata Memorial Hospital, Mumbai, India; Dr Nene and Dr M Basade, Barshi Cancer Hospital, Sholapur, India; Dr AM Ranbhise, Wanless Hospital, Miraj, India; Dr Rao, Sangli Civil Hospital, Sangli, India; Dr Lingaswamy, Ruby Hall Clinic, Poona, India; Dr SJ Bhonsale, Dr HR Tata, and Dr P Somaiya, KH and MRC, Karad, India; Mr BR Patil and Mr Sanjay Patil, Sugar Cane Workers Federation, Karad, India. This project was supported in part by funding received from the Government of the province of Maharashtra, India.

1 Fox RL, Silva JA, Plucknett DL, et al. Soluble and total silicon in sugar cane. Plant Soil 1969;30:81-92.

2 Newman RH. Asbestos like fibres of biogenic silica in sugar cane. Lancet 1983;ii:857.

3 Rabovsky J. Biogenic amorphous silica. Scand 7 Work Environ Health 1995;21(suppl 2):108-10.

4 Bhatt TS, Coombs M, O'Neill C. Biogenic silica fiber promotes carcinogenesis in mouse skin. Int f Cancer 1984;34: $519-28$.

5 Bhatt TS, Lang S, Sheppard MN. Tumors of mesothelial origin in rats following innoculation with biogenic silica fibers. Carcinogenesis 1991;12:1927-31.

6 O'Neill CH, Hodges GM, Riddle P, et al. A fine fibrous silica contaminant of flour in the high oesophageal cancer area of North-East Iran. Int $\mathcal{F}$ Cancer 1980;26:617-28.

7 Rose EF. Carcinogens and oesophageal insults. S Afr Med 7 1968;42:334-6.

8 Burkitt D. Epidemiological features of gastro-intestinal cancer. In: Rozen P, Eidelman S, Gilat R, eds. Gastrointestinal cancer. Advances in basic research. Basel: Karger, 1979:8695.

9 O'Neill CH, Quiong-Qing P, Clarke GD, et al. Silica fragments from millet in mucosa surrounding oesophageal fragments from millet in mucosa surrounding oesophageal
tumors in patients in northern China. Lancet 1982;i: 1201-6.

10 McCurdy SA, Fergusson TJ, Goldsmith DF, et al. Respiratory health of California rice farmers. Am $\mathcal{F}$ Respir Crit Care Med 1996;153:1553-9.

11 Boeniger MF, Hawkins M, Marsin P, et al. Occupational exposure to silicate fibers and PAHs during sugar cane harvesting. Ann Occup Hyg 1988;32:153-9.

12 Boeniger MF, Fernback J, Hartle R, et al. Exposure assessment of smoke and biogenic silica fibers during sugar cane harvesting in Hawaii. Appl Occup Environ Hyg 1991;6: 59-66.

13 Lawson RJ, Schenker SA, McCurdy B, et al. Exposure to amorphous silica fibers and other particulate matter during rice farming operations. Appl Occup Environ Hyg 1995;10: 677-84.

14 Das PB, Fletcher AG, Deodhare SG. Mesothelioma in an agricultural community in India. A clinocopathological agricultural community in India. A clinc
study. Aust N Z F Surg 1976;46:218-26.

15 Rothschild H, Mulvey JJ. An increased risk for lung cancer mortality associated with sugar cane farming. $\mathcal{F}$ Natl Cancer Inst 1982;68:755-60.

16 Brooks SM, Stockwell HG, Pinkham PA, et al. Sugar cane exposure and the risk of lung cancer and mesothelioma. Environ Res 1992;58:195-203.

7 Miller WF, Reed DM, Banta J. Sugar cane workers: morbidity and mortality. Hawaii Med f 1993:52:300-6.

18 Sinks T, Goodman MT, Kolonel LN, et al. A case-control study of mesothelioma and employment in the Hawaii sugar cane industry. Epidemiology 1994;5:466-8.

19 Sugar industry in Maharashtra. Maharashtra rajya sahakari sakhar karkhana sangh. 11th floor, Nariman Point, Mumbai-21: Sakhar bhavan, 1996.

20 Hosmer DW Jr, Lemenshow S. Applied logistic regression. New York: John Wiley, 1989.

21 Cooper WC, Cralley LJ. Pneumoconiosis in diatomite mining and processing. Washington (DC): US Department of Health, Education and Welfare, 1958. (PHS No 601.)

22 Vainio H, Boffeta P. Mechanisms of the combined effect of asbestos and smoking in the etiology of lung cancer. Scand $f$ Work Environ Health 1994;20:235-42.

23 Barthel E. Increased risk of lung cancer in pesticide exposed male agricultural workers. $\mathcal{F}$ Toxicol Environ Health 1981;8: 1027-40.

24 Axelson O. Pesticides and cancer risks in agriculture. Medical Oncology and Tumour Pharmacotherapy 1987;4:207-17.

25 De Stephani E, Kogevinas M, Boffeta P, et al. Occupation and the risk of lung cancer in Uruguay. Scand 7 Work Environ Health 1996;22:346-52. 